\title{
ПРИНЦИПИ ПОБУДОВИ ЕФЕКТИВНОГО ОНЛАЙН-НАВЧАННЯ
}

\author{
Боднар Т. $\mathrm{O}$. \\ аспірант кафедри педагогіки та інновачійної освіти \\ Начіональний університет «Львівська політехніка» \\ вул. Степана Бандери, 12, Львів, Україна \\ orcid.org/0000-0002-1497-5955 \\ tanyabodnar15@ukr.net
}

Ключові слова: віртуальна освіта, зворотній зв'язок, організачія навчального проиесу, співпраця викладачстудент, інформаційні технологї.
У даній статті розглядається проблема ефективності під час навчального процесу у віртуальному середовищі. Доведено, що за сучасних тенденцій, коли студенти і освітяни все частіше зустрічаються 3 цифровою дистанційною освітою, супутньою проблемою постає втрата мотивації та ефективності під час віддаленого навчання. У зв'язку з пандемією, що видозмінила навчальний процес, перехід на навчання в онлайн форматі був необхідним, і таке поняття, як ефективність, під час віртуального навчання поступово втрачається, від чого в діях студентів почала прослідковуватись мінімальна залученість, взаємодія 3 викладачами та одногрупниками в ході лекцій/практичних, та нерідко стикаються 3 поняттям прокрастинації. Після введення обмежень відвідування закладів вищої освіти кількість обговорень, запитів в глобальній мережі про те, як залишатись продуктивним перебуваючи на дистанційному віртуальному навчанні, значно зросла. Сьогодні відсутні чіткі правила чи стандарти продуктивного навчання онлайн. У даній статті було проаналізовано принципи, критерії побудови ефективного онлайн-навчання для студентів та викладачів, зокрема: експертність, змістовність, формат проведення, зворотній зв'язок та інші на основі думок американських дослідників, освітян та практик американських університетів, які здійснювали власні дослідження проблеми впливу цифрових технологій на мотивацію студентів та викладачів у вищій освіті. Було детально розглянуто основні дев'ять принципів побудови ефективного онлайн-навчання 3 метою переконання в тому, що інформаційні технології завжди займатимуть місце в житті сучасного студента та викладача, відповідно, з нашого боку $\epsilon$ потреба розвитку власної гнучкості, адаптивності в нових навчальних умовах, при цьому, в результаті, залишатись продуктивними, вмотивованими, з якісними знаннями. Пропонується безліч варіантів, як не втратити ефективності, отримуючи-подаючи навчальний матеріал крізь екран монітору, які варто проаналізувати і за можливості використовувати на практиці для успішного подання та отримання знань. 


\title{
PRINCIPLES OF EFFECTIVE ONLINE LEARNING
}

\author{
Bodnar T. O. \\ Postgraduate Student at the Department of Pedagogy and Innovative Education \\ Lviv Polytechnic National University \\ S. Bandery str., 12, Lviv, Ukraine \\ orcid.org/0000-0002-1497-5955 \\ tanyabodnar15@ukr.net
}

Key words: virtual education, feedback, organization of the educational process, teacherstudent cooperation, information technologies.

\begin{abstract}
This article discusses the effectiveness issue during a learning process in a virtual environment. It has been proved that with modern trends when students and teachers are increasingly encountered with digital distance education, a concomitant problem arises a loss of motivation and efficiency during remote training. Due to the pandemic that modified the educational process, the transition to online learning was necessary and such a concept as efficiency during virtual learning is gradually lost, from which minimal involvement, interaction with teachers and classmates during lectures/practical, began to be traced in the actions of students, and often face the concept of procrastination. After the introduction of restrictions on attending higher education institutions, the number of discussions, requests on the global network about how to remain productive while in remote virtual training has increased significantly. To date, there are no clear rules or standards for productive online training. This article analyzed the existing principles, criteria for building effective online learning for students and teachers, in particular: expertise, content, format of conduct, feedback, and other based on the opinions of American researchers, teachers, and practices of American universities, who carried out their own research into the impact of digital technologies on the motivation of students and teachers in higher education. The main nine principles of building effective online learning were discussed in detail in order to convince that information technology will always occupy a place in the life of a modern student and teacher, accordingly on our part there is a need to develop our own flexibility, adaptability in new educational conditions, while, as a result, remaining productive, motivated, with high-quality knowledge. Many options are offered by researches as not to lose efficiency in receiving and supplying educational material through the monitor screen, which should be analyzed and, if possible, used in practice for successful presentation and acquisition of knowledge.
\end{abstract}

Постановка проблеми. Сучасний світ складно уявити без впливу інформаційних технологій. Освітня сфера не є виключенням. Із кожним роком технології в освіті набувають стрімкого розвитку та набувають вагомості в організації навчального процесу. Із появою пандемії, технології та освіта стали фактично одним цілим. У «доковідний» період життя сучасного студента та викладача було організованим, передбачуваним та дисциплінованим по відношенню до навчання. Під впливом сучасних карантинних реалій, нового «домашнього» стилю студентської взаємодії з закладами вищої освіти студенти стали менш ефективні та залучені до здобуття знань на належному рівні. Проте, незважаючи на зміну формату навчання, проблема формування ефективності навчального процесу, необхідності перебування в ресурсі, при- ділення потрібної кількості часу для навчання та способу отримання нових знань стає дедалі поширенішою. Щоб зберегти мотивацію та уникнути прокрастинації стосовно навчального процесу в онлайн-умовах, пропонується низка підходів, алгоритмів дій, принципів збереження продуктивності здобуваючи знання у віртуальному середовищі. Проблема ефективності онлайн-навчання серед студентів та викладачів досліджується багатьма науковцями, лідерами думок в освітній галузі, в тому числі дану проблематику вивчають такі зарубіжні представники: Chickering, A. W., Gamson, Z. F., Ehrmann, S. C., Bolliger, D. U., Berge, Z. L., Bangert, A. W., Gallien, T., Gedik, N., Kiraz, E., Ozden, M. Y., Hathaway, K. L., Hewson, E. R. F., Johnson, S., Lewis, C. C., Moore, M. J., Morrison, D., Plante, K., Asselin, M. E., Schwie- 
bert, C., Young, S., Oakley B. та інші [1-17]. Слід детальніше підійти до аналізу підходів від вищезгаданих науковців, спрямованих для підтримки ефективності навчального процесу в онлайн-середовищі.

Мета статті - проаналізувати наявні принципи побудови ефективного онлайн-навчання для студентів та викладачів 3 метою розуміння, що віртуальна освіта може бути рівноцінно продуктивною та організованою до традиційного аудиторного формату.

Виклад основного матеріалу дослідження. Із появою глобальної проблеми людства, Covid-19, в нашому світі пандемія змусила всіх переглянути спосіб життя в різних суспільних сферах, і освіта не стала виключенням. Після введення обмежень відвідування закладів вищої освіти, кількість обговорень, запитів в глобальній мережі про те, як залишатись продуктивним, перебуваючи на дистанційному віртуальному навчанні, значно зросла. На жаль, сьогодні день немає уніфікованих правил, стандартів, як навчатись онлайн і при цьому не втрачати власної продуктивності та мети до навчання загалом. Представники освіти на постійній основі намагаються надати допомогу в адаптації до будь-якого типу навчання, традиційного чи дистанційного (мережевого). Для цього слугують відповідна література, різноманітні освітні форуми, групи, спільноти, соціальні мережі тощо. Розглядаючи проблему ефективності навчання в мережі з точки зору американських дослідників та університетів США, маємо такі думки. Університет Аризони спільно 3 компанією «Boston Consulting Group (BCG)» зробили власний аналіз проблеми цифрових технологій у вищій освіті. Було взято до уваги біля шести американських закладів вищої освіти, де прослідковувалась успішність студентів, які здійснювали навчання в традиційному форматі, і студентів, які практикували змішане навчання. Після порівняння двох форматів навчання було підведено висновок, що можливості успішного завершення того чи іншого навчального курсу зростали, якщо його студенти проходили онлайн або зі допомогою змішаного типу. Барбара Оуклі, професорка інженерії Оклендського університету, запропонувала свої підходи до ефективної організації навчального процесу онлайн для викладачів, оскільки ефективність онлайн-навчання полягає у наполегливій праці не лише студентів, а ще і самих викладачів. Отже, ці підходи було розподілено на три критерії: експертність, змістовність та формат проведення.

Говорячи про експертність, маємо на увазі стиль подання навчального матеріалу. Від цього залежить безліч моментів, які забезпечують успіх засвоєння матеріалу, а також заохочення студентів бути проактивними учасниками навчального процесу. Б. Оуклі рекомендує не виглядати зверхньо перед камерою. Не має потреби показувати великий багаж знань, проте натомість краще розповісти менше, але зрозуміліше. Тому слід користуватись простою і доступною мовою, щоб можна було втримати увагу студентів, що $є$ доволі непросто. Перед цим можна спробувати потренуватись перед людьми, які не знайомі з темою і визначити, як легко вони сприйняли прослухану інформацію. Потрібно сформувати текст таким чином, щоб він став доступнішим для широкої аудиторії. Також рекомендується застосовувати більше прикладів, порівнянь або ж метафор. Щоб зробити порівняння значно простішими та зрозумілими, рекомендовано використовувати ілюстрації та/або матеріали, доповнені анімацією. Будь-який рух на відео привертає увагу слухача, а жарти до того ж налаштовують на позитивний лад. Це важливо, адже онлайн-курс переглядають 3 комп'ютера чи інших девайсів - можна легко відволіктися на месенджери, соціальні мережі. Тому варто робити акцент на «живу» взаємодію зі студентами - так викладач допоможе слухачеві сконцентруватися на відеоматеріалі. До речі, гумор можна додати не лише у відео. Тексти-привітання, тести та розв'язування додаткових задач - гумор, доречний завжди.

Змістовність. Навчальний контент, що подається викладачем, повинен грунтуватись на авторитетних, актуальних та релевантних джерелах.

Формат подання матеріалу. Слід виключати все зайве, що може перевантажити слухача інформаційно. Короткі відео до 5-6 хвилин, доповіді комбіновані $з$ жартами та цікавими фактами можуть забезпечити значно більший ефекту від лекції, ніж стандартне озвучування 20-50 листів поспіль «сухого» тексту-монологу. Грамотний розподіл матеріалу заохочує навчатися. Такий підхід стимулює та втримує мотивацію студента на тривалий час [18].

Зворотній зв'язок. Визнаючи саму природу спілкування в онлайн-середовищі, викладачам слід бути уважними і вчасно реагувати на електронні листи чи текстові повідомлення в соціальних мережах, студентських групових чатах тощо. Важливо завжди надавати зворотній зв'язок стосовно будь-якої роботи виконаної студентами. Забезпечуючи зворотній відповідь вчасно, викладач уникає потенційних проблем, з якими стикаються студенти в ході вивчення того чи іншого навчального матеріалу, і допомагає вчасно зрозуміти та краще вникнути в інформацію та просунутись у навчанні далі [19].

Зворотній зв'язок можна здійснювати за такими критеріями, як екологічність, конкретика та можливість застосування на практиці. Під поняттям екологічності в даному контексті йдеться про 
демонстрування ставлення до роботи чи ідеї, яку подав студент. Не критикувати. Потрібно зрозуміти, які емоції викликали ті чи інші дії з боку студента, і тактовно проговорити свої враження від ідеї чи виконаної роботи. Конкретика - слід уточнити, чому це завдання/проект варто доопрацювати, які конкретно моменти сподобалися, а які викликали сумнів, чому не можна залишити як $\epsilon$ i не виправляти. Можливість застосування на практиці передбачає надання порад, рекомендацій із приводу відповідного завдання чи запиту студента 3 того чи іншого запитання. Однак ці поради необхідно подавати об'єктивно та делікатно. Наприклад, викладачу важливо поставити себе на місце студента, щоб дати більш конструктивні поради, знизити рівень суб'єктивності і свого особистого ставлення до студента 3 метою не викликати негативних емоцій та скептицизму до професіоналізму викладача з боку студента.

Для ефективного навчання безпосередньо самих студентів представники Північно-Східного університету (м. Бостон) пропонують до використання такі принципи організації продуктивного навчання. Перший принцип - організованість. Перед початком навчання потрібно переконатися, що $є$ всі технічні можливості отримання доступу до необхідних матеріалів курсу, включаючи електронні книги, онлайн-інструменти, програми, системи тощо. Слід виділити час, щоб попрактикуватися в навігації онлайн-систем, щоб підготуватися до першого заняття. Таким чином, студент може зосередитися на навчанні, а не намагатися увійти в лекцію через п'ять хвилин. Крім того, як і у фізичному класі, слід переконатися студенту в тому, що під рукою є матеріали для надійних нотаток. Ведення записів про роботу протягом семестру стане в нагоді під час випускних іспитів. Другий принцип - налаштування особистого робочого простору. Необхідно створити спеціальне середовище для навчання. Виконуючи там свою роботу кілька разів, сформується звичка встановлювати розпорядок дня. Не всі студенти однакові - одні найкраще працюють, слухаючи музику, а іншим потрібні тиша і спокій. Варто провести експеримент, щоб дізнатися, який тип налаштування підвищує продуктивність. Вибираючи робоче місце, слід обмежити відволікаючі фактори, як фізично, так і онлайн. Сьогодні в інтернеті можна знайти безліч спеціальних онлайн-додатків, програм, які дозволяють не втрачати концентрацію та увагу до процесу навчання, до прикладу програми Freedom, Forest, OmniFocus, Magnet, Pomodoro та інші. Третій принцип - визначення періоду ефективності навчання. Варто для себе зрозуміти, дослідити, коли і в який період доби працюється найкраще - ранок, обід і вечір. Відповідно, в комфортний період необхідно фокусувати свої зусилля на виконанні тих чи інших завдань. Четвертий принцип - тайм-менеджмент. Слід розподілити своє робоче навантаження на частини, присвячуючи певні години щотижня читанню, перегляду лекцій, виконанню завдань тощо. Потім встановити нагадування про виконання завдань. Потрібно ставитись до цих часових проміжків так само серйозно, як до особистого заняття, даючи іншим знати, що студент недоступний в той чи інший час і постійно використовуючи відведений власний робочий простір. Рекомендовано залучати таймер і дозволяти собі переходити до інших завдань, коли час завершиться. П'ятий принцип активна життєва позиція. Ініціативність дорівнює успіху. Читання матеріалів, періодичні звернення до одногрупників та/або викладачів, а також проведення додаткових досліджень за необхідності. Студенти, які приділяють час для комунікації 3 викладачами i одногрупниками, зазвичай досягають найбільших успіхів у навчанні. Шостий принцип - залишатись на зв'язку. Варто налагоджувати стосунки з іншими студентами, беріть активну участь у студентському онлайн-житті. Існує потреба ставити запитання і відповідати на них, щоб краще зрозуміти матеріал курсу і налагодити зв'язок $з$ іншими студентами. Однолітки можуть бути цінним ресурсом у підготовці до іспитів або під час запиту відгуків про завдання. Не потрібно соромитись звертатися до викладачів, щоб вони представилися під час першої лекції, або ж поставити питання до них. Насправді викладачі часто виявляють бажання спілкуватись зі своїми студентами онлайн або ж особисто. Сьомий принцип - відкритість. Деяким студентами зручніше ділитися своїми думками віртуально, ніж в аудиторії. Онлайн-навчання дає можливість для того, щоб осмислити і систематизувати свої думки, перш ніж відповісти на питання або зробити коментар. Відкритість допомагає студентам взаємодіяти один з одним та викладачами і сприяє більш залученій і відкритій науковій співпраці. Восьмий принцип - запитання. Не слід боятися ставити запитання викладачам, просити роз'яснення щодо тієї чи іншої темі навчання, потребувати поради. Так зникає можливість плутанини, студенти стають більш залученими до змісту теми, розширюють свої знання і поглиблюють стосунки зі своїми одногрупниками та викладачами. Публікація повідомлень в чатах групи також дозволяє краще зрозуміти суть тієї чи іншої теми та налагодити плідну кооперацію з іншими викладачами і студентами. Викладачі, як правило, заохочують такий тип взаємодії і цінують створювану студентами згуртованість. Дев'ятий принцип - відповідальність. $Є$ необхідність у постановці ключових цілей на початку семестру, власній перевірці щотижня та аналізі фінального 
результату. У традиційній аудиторії, як правило, часто отримуються усні або візуальні нагадування про наближення терміну виконання завдання. Однак без активного нагадування від викладача постає потреба в особистій перевірці для того, щоб студентом було виокремлено достатньо часу для завершення роботи, щоб він не приступив до виконання завдання за день до завершення його терміну. Будучи організованим та залученим, студент має можливість отримати максимальну віддачу від свого онлайн-класу та процесу навчання загалом, навіть коли життя за межами університету стає стрімким та хаотичним [20].

Висновки. Із дослідження проблеми принципів побудови ефективного онлайн-навчання студентів та викладачів можемо зробити певні висновки. Усі ми звикли до традиційного аудиторного навчання, і не кожен вважає, що цифрова освіта може бути ефективною. Однак слід розуміти той факт, що бути продуктивним необхідно завжди, незалежно від типу навчання. Гнучкість та здатність до швидкої адаптації в будь-яких умовах $\epsilon$ ключовими критеріями суспільства XXI століття. Інформаційні технології поглинатимуть освітню сферу все більше і більше, тому у випадку викладачів є лише один шлях - це шлях постійного розвитку, вдосконалення нових педагогічних технологій і навичок, максимально швидкої адаптації під нові освітні реалії, а студентам слід постійно вчитись і працювати над собою, намагатись знаходити свої ефективні методи у дистанційному навчанні, і розпочати ці пошуки можна вже з готових пропонованих науковцями принципів побудови продуктивного навчання.

\section{ЛІТЕРАТУРА}

1. Chickering, A. W., Gamson, Z. F. (1987) 'Seven principles of good practice in undergraduate education', AAHE Bulletin, vol. 39, no. 7, pp. 3-7.

2. Ehrmann, S. C. (1996) 'Implementing the seven principles: tech-nology as lever', AAHE Bulletin, vol. 49, no. 2, pp. 3-6.

3. Bolliger, D. U., Des Armier, D. (2013) 'Active learning in the online environment: the integration of student-generated audio files', Active Learning in Higher Education,vol. 14, no.3, p. 211.

4. Berge, Z. L. (2002) 'Active, interactive, and reflective eLearning', The Quarterly Review of Distance Education, vol. 3, no. 2, pp. 181-190.

5. Bangert, A. W. (2004) 'The Seven Principles of Good Practice: a framework for evaluating on-line teaching', Internet and Higher Education, vol. 7, pp. 217-232.

6. Gallien, T. (2008) 'Personalized versus collective instructor feedback in the online classroom: does type of feedback affect student satisfaction, academic performance and perceived connectedness with the instructor?', International Journal on e-learning, vol. 7, no. 3, pp. 463-476.

7. Gedik, N., Kiraz, E., Ozden, M. Y. (2013) 'Design of a blended learning environment: considerations and implementation issues', Australasian Journal of Educational Technology, vol. 29, no. 1. pp. 1-19.

8. Hathaway, K. L. (2014) 'An application of the seven principles of good practice to online courses', Research in Higher Education Courses, vol. 22, pp. 1-12.

9. Hewson, E. R. F. (2018) 'Students' emotional engagement, motivation and behaviour over the life of an online course: reflections on two market research case studies', Journal of Interactive Media in Education, vol. 1 , no. 10 , pp. 1-13.

10. Johnson, S. (2014) 'Applying the seven principles of good practice: technology as a lever - in an online research course', Journal of Interactive Online Learning, vol. 13, no. 2, pp. 41-50.

11. Lewis, C. C. (2006) 'Implementing effective online teaching practices voices of exemplary faculty', Innovative Higher Education, vol. 31, no. 2, pp. 83-98.

12. Moore, M. J. (1993) 'Three types of interaction', in Distance Education: New Perspectives,eds K. Harry, M. John \& D. Keegan, Routledge, New York, pp. 19-24.

13. Morrison, D. (2015) Four-Step Strategy to Create Active Learning in Any Learning Space - Learning Insights.

14. Plante, K., Asselin, M. E. (2014) 'Best practices for creating social presence and caring behaviors online', Nursing Education Perspectives, vol. 3, no. 4, pp. 219-223.

15. Schwiebert, C. (2012) The 7 Principles of Online Learning. Are They Still Valid?

16. Young, S. (2006) 'Student views of effective online teaching in Higher Education', The American Journal of Distance Education, vol. 20, no. 2, pp. 65-77.

17. Oakley B., Sejnowski T. J. (2019) 'What we learned from creating one of the world's most popular MOOCs', NPJ, Science of learning, pp. 1-7

18. Oakley B., Kris D.F. (2017) '5 Strategies to Demystify the Learning Process for Struggling Students'. URL : https://www.kqed.org/mindshift/49697/5-strategies-to-demystify-the-learning-process-for-struggling-students. 
19. Bailey C.J., Card K.A.(2009) 'Effective pedagogical practices for online teaching: Perception of experienced instructors', The Internet and Higher Education vol. 12, no.3, pp. 152-155.

20. Joubert S. (2020) 'How to Be a Successful Online Learner: 9 Tips \& Strategies'. URL : https://www.northeastern.edu/bachelors-completion/news/successful-online-learning-strategies/.

\section{REFERENCES}

1. Chickering, A. W., Gamson, Z. F. (1987) 'Seven principles of good practice in undergraduate education', AAHE Bulletin, vol. 39, no. 7, pp. 3-7.

2. Ehrmann, S. C. (1996) 'Implementing the seven principles: tech-nology as lever', AAHE Bulletin, vol. 49, no. 2, pp. 3-6.

3. Bolliger, D. U., Des Armier, D. (2013) 'Active learning in the online environment: the integration of student-generated audio files', Active Learning in Higher Education,vol. 14, no.3, p. 211.

4. Berge, Z. L. (2002) 'Active, interactive, and reflective eLearning', The Quarterly Review of Distance Education, vol. 3, no. 2, pp. 181-190.

5. Bangert, A. W. (2004) 'The Seven Principles of Good Practice: a framework for evaluating on-line teaching', Internet and Higher Education, vol. 7, pp. 217-232.

6. Gallien, T. (2008) 'Personalized versus collective instructor feedback in the online classroom: does type of feedback affect student satisfaction, academic performance and perceived connectedness with the instructor?', International Journal on e-learning, vol. 7, no. 3, pp. 463-476.

7. Gedik, N., Kiraz, E., Ozden, M. Y. (2013) 'Design of a blended learning environment: considerations and implementation issues', Australasian Journal of Educational Technology, vol. 29, no. 1. pp. 1-19.

8. Hathaway, K. L. (2014) 'An application of the seven principles of good practice to online courses', Research in Higher Education Courses, vol. 22, pp. 1-12.

9. Hewson, E. R. F. (2018) 'Students' emotional engagement, motivation and behaviour over the life of an online course: reflections on two market research case studies', Journal of Interactive Media in Education, vol. 1 , no. 10 , pp. 1-13.

10. Johnson, S. (2014) 'Applying the seven principles of good practice: technology as a lever - in an online research course', Journal of Interactive Online Learning, vol. 13, no. 2, pp. 41-50.

11. Lewis, C. C. (2006) 'Implementing effective online teaching practices voices of exemplary faculty', Innovative Higher Education, vol. 31, no. 2, pp. 83-98.

12. Moore, M. J. (1993) 'Three types of interaction', in Distance Education: New Perspectives,eds K. Harry, M. John \& D. Keegan, Routledge, New York, pp. 19-24.

13. Morrison, D. (2015) Four-Step Strategy to Create Active Learning in Any Learning Space - Learning Insights.

14. Plante, K., Asselin, M. E. (2014) 'Best practices for creating social presence and caring behaviors online', Nursing Education Perspectives, vol. 3, no. 4, pp. 219-223.

15. Schwiebert, C. (2012) The 7 Principles of Online Learning. Are They Still Valid?

16. Young, S. (2006) 'Student views of effective online teaching in Higher Education', The American Journal of Distance Education, vol. 20, no. 2, pp. 65-77.

17. Oakley B., Sejnowski T. J. (2019) 'What we learned from creating one of the world's most popular MOOCs', NPJ, Science of learning, pp.1-7

18. Oakley B., Kris D.F. (2017) '5 Strategies to Demystify the Learning Process for Struggling Students'. URL:https://www.kqed.org/mindshift/49697/5-strategies-to-demystify-the-learning-process-for-struggling-students

19. Bailey C.J., Card K.A.(2009) 'Effective pedagogical practices for online teaching: Perception of experienced instructors', The Internet and Higher Education vol. 12, no.3, pp.152-155.

20. Joubert S. (2020) 'How to Be a Successful Online Learner: 9 Tips \& Strategies'.URL:https://www.northeastern.edu/bachelors-completion/news/successful-online-learning-strategies/ 